\title{
Productivity of a preparative high-performance liquid chromatography isolation of anacardic acids from cashew nut shell liquid
}

\author{
Francisco Oiram Filho $^{1}$ | Guilherme J. Zocolo ${ }^{2}$ | Kirley M. Canuto ${ }^{2}$ | \\ Ivanildo J. da Silva Junior ${ }^{1} \quad$ Edy S. de Brito ${ }^{2}$ (iD
}

${ }^{1}$ Department of Chemical Engineering, Universidade Federal do Ceará, Fortaleza, CE, Brazil

${ }^{2}$ Embrapa Agroindústria Tropical, Fortaleza, CE, Brazil

\section{Correspondence}

Dr. Edy Sousa de Brito, Embrapa Agroindústria Tropical, 2270, Pici, Fortaleza, CE, 60511 110, Brazil.

Email: edy.brito@embrapa.br

The anacardic acids are alkyl phenols, with biological activities, obtained as a byproduct from cashew nut processing. The anacardic acids isolation by preparative reversed phase high-performance liquid chromatography was developed injecting large pulse from 50 to $200 \mathrm{mg}$ of cashew nut shell liquid through a $\mathrm{C}_{18}$ column eluted with methanol, water and acetic acid (80:20:1). The separations were carried out at $25^{\circ} \mathrm{C}$ and monitored at $280 \mathrm{~nm}$. Yield, recovery, purity, solvent consumption and productivity were analyzed. The results of anacardic acids isolation pointed the concentration loading of $100 \mathrm{mg}$ as a process threshold leading to a productivity of $0.681 \mathrm{Kg} . \mathrm{day}^{-1} \cdot \mathrm{Kg}^{-1}$ of anacardic acids with purity of $96.41,95.32$ and $90.77 \%$ for anacardic acid triene, diene and monoene, respectively.

\section{K E Y W O R D S}

alkyl phenols, Anacardium occidentale, concentration overloading, ginkgolic acid, preparative chromatography, purification

\section{1 | INTRODUCTION}

The anacardic acids (AnAc) are phenolic compounds derived from salicylic acid with an alkyl side chain. The AnAc are

Article Related Abbreviations: $\%_{\text {sol }}$, percentage of organic solvent present in the mobile phase; $(\%) R_{p r}$, recovery; AnAc, anacardic acids; AnAc (I), anacardic acid triene (C15:3); AnAc (II), anacardic acid diene (C15:2); AnAc (III), anacardic acid monoene (C15:1); $C_{A n A c}$, anacardic acids concentration (mg.mL ${ }^{-1}$ ); CNSL, cashew nut shell liquid; $d c_{1}$, diameter of analytical column; $d c_{2}$, diameter of preparative column; $d p_{1}$, diameter particle of analytical column; $d p_{2}$, diameter particle of preparative column,; $L_{1}$, length of analytical column; $L_{2}$, length of preparative column; $L_{i n j}$, concentration loading; $\log \mathrm{D}$, distribution coefficient; $\log \mathrm{P}$, partition coefficient; $m_{a d}$, column adsorbent mass; $m_{a n}$, mass of each AnAc present in $1 \mathrm{mg}$ of CNSL; $m_{A n A c}$, mass of anacardic acids; $m_{\text {theo }}$, theoretical mass of each AnAc in preparative scale; $P r$, productivity of insolation on the preparative system; PTFE, Polytetrafluorethylene; $Q$, flow $\left(\mathrm{mL} . \mathrm{min}^{-1}\right) ; S C$, solvent consumption expressed in $\mathrm{mL} \cdot \mathrm{mg}^{-1}$ of anacardic acids; $t_{\text {run }}$, time of chromatographic run; $V_{i n j 1}$, volume injection of analytical scale; $V_{i n j 2}$, volume injection of preparative scale. found in all parts of the cashew apple tree (Anacardium occidentale) such as bark, leaf, cashew apple (pseudo-fruit), and nut; but especially on the nut shell. The cashew nut shell liquid (CNSL) is a viscous brownish liquid contained into cashew nut shell constituted mainly by AnAc, being by far the larger known natural source of these compounds [1].

The AnAc hydrophobicity are influenced by the alyphatic chain length, which can vary from 2 to 17 carbons [2-4], yet AnAc containing 15 carbons side chain are the main compounds on CNSL. A further important structural feature of AnAc molecules is the aliphatic chain unsaturation degree, varying from 0 to 3 unsaturations [5]. The AnAc biological activity is highly influenced by these structural differences [6, 7]. The AnAc are a class of compound with different activities such as anti-carcinogenic activity [8], anticholinesterase inhibition [9], antiprotozoal [10], bactericide [11] and antioxidant activities [12].

The isolation of natural compounds with biological activities is usually made by chromatography techniques. HPLC 
has two major modes analytical and preparative. The analytical scale is suitable for analytical purposes, since it uses minor volumes, low concentration, and low flow rate. In the other hand, the use of preparative scale stands out as a versatile and fast tool capable to isolate high-purity bioactive compounds from complex mixtures such as plant extracts [13]. One of its fundamental characteristics is the possibility of injection of high volumes or concentrations [14], besides that this scale might use a high flow rate leading to a higher pressure, allowing to obtain purified compounds in a larger scale, resulting in a higher productivity and lower process costs $[15,16]$. However, this scaling-up should be done sparingly, since loading column capacity may affect separation performance causing compounds coelution due to the column saturation. A high concentration loading injection as well as robustness, reproducibility and versatility on purification of bioactive compounds make preparative HPLC a primordial approach for natural products isolation [17]. In this regard, several bioactive compounds have been isolated by preparative scale HPLC such as, flavonoids [18], saponins [19] and other natural compounds from medicinal plants [20].

There is a great interest of pharmacy industry on AnAc due its biological activities, however, there are few studies of isolation on preparative scale of AnAc [21,22], besides that some important parameters such as solvent consumption, productivity, yield, recovery, purity and threshold saturation have not been defined yet. Thus, the aim of this work was to establish these parameters for better conditions with high productivity and low cost on the AnAc isolation process by preparative reversed phase HPLC.

\section{2 | MATERIAL AND METHODS}

\section{1 | Chemicals and materials}

The following reagents were employed: HPLC grade methanol (Merck, Darmstadt, Germany) and analytical grade glacial acetic acid (Synth, São Paulo, Brazil), besides anacardic acids (15:3, 15:2 e 15:1) isolated previously from CNSL and used as analytical standards [23]. The cashews harvested at Embrapa Agroindústria Tropical experimental field (Pacajus-CE, Brazil) were dried in a forced air dryer at $40^{\circ} \mathrm{C}$ for $96 \mathrm{~h}$. For obtaining the shells, the cashews were manually cut (longitudinal) using a blade. Afterwards, The CSNL was obtained by pressing the shells on a hydraulic press (Marconi MA/098/50A/I, Piracicaba, SP, Brazil) under the following conditions, $15 \mathrm{MPa}$ for three min at $40^{\circ} \mathrm{C}$ resulting a CNSL yield of $40 \%(\mathrm{~m} / \mathrm{m})$. Samples of CNSL were solubilized in methanol at four different concentrations $\left(50,75,100\right.$ and $\left.200 \mathrm{mg} \cdot \mathrm{mL}^{-1}\right)$ and filtered through $0.45 \mu \mathrm{m}$ PTFE membranes.

\section{2 | Anacardic acids physico-chemical parameters}

The AnAc physico-chemical parameters partition coefficient $(\log \mathrm{P})$, distribution coefficient $(\log \mathrm{D})$ and solubility were calculated using the software chemicalize.com [24].

\section{3 | Preparative HPLC}

A HPLC system consisting of a quaternary gradient module (Waters 2555) coupled to an UV detector (Waters 2489) and fraction collector (Waters Fraction Collector III (Dublin, Leinster, Ireland) was used. It was equipped with a reverse phase column C18 $(100 \times 19 \mathrm{~mm}, 5 \mu \mathrm{m}$, Waters SunFire Prep).The AnAc peaks were collected at the following retention times from 13.2 to $17.9 \mathrm{~min}$, from 18.6 to $24.2 \mathrm{~min}$ and from 26.6 to 34.5 min for anacardic acids triene, diene and monoene, respectively.

An analytical method developed by our research group earlier [23] was transferred to the preparative scale according to the equations (1) and (2), described on literature [25,26], were used to measure volume injection and flow rate.

$$
V_{i n j 2}=V_{i n j 1} \cdot \frac{d c_{2}^{2}}{d c_{1}^{2}} \cdot \frac{L_{2}}{L_{1}}
$$

Wherein, $V_{i n j 2}$ is volume injection of preparative scale, $V_{i n j 1}$ is volume injection of analytical scale, $d c_{2}$ is diameter of preparative column, $d c_{1}$ is a diameter of analytical column, $L_{1}$ is a length of analytical column and $L_{2}$ is the length of the preparative column.

$$
Q_{2}=Q_{1} \cdot \frac{d c_{2}^{2}}{d c_{1}^{2}} \cdot \frac{d p_{1}}{d p_{2}}
$$

Wherein, $Q_{2}$ is flow rate elution of preparative scale, $Q_{1}$ is flow rate elution of analytical scale, $d c_{2}$ is diameter of preparative column, $d c_{1}$ is a diameter of analytical column, $d p_{2}$ is diameter particle of preparative column, $d p_{1}$ is a diameter particle of analytical column.

The conditions of the analytical and preparative methods are compared in Table 1. The parameters of flow, mobile phase and proportion of organic solvent were adjusted. The choice of the organic solvent and mobile phase proportion were based on Snyder nomogram [27] which provides a comparison between organic solvents considering its polarity; and the choice of organic solvent was taking into account environmental and economic factors. The chromatography was performed on an isocratic mode using a mobile phase of methanol and water (90:10\% v/v) both acidified with acetic acid (1\%), $10 \mathrm{~mL} . \mathrm{min}^{-1}$, for $40 \mathrm{~min}$ at $25^{\circ} \mathrm{C}$; and a fixed injection volume of $1 \mathrm{~mL}$, all injections were done in triplicate. The chromatograms were monitored at a wavelength of $280 \mathrm{~nm}$. The 
TA B L E 1 The initial conditions of analytical method and optimum conditions of preparative method used after scale up

\begin{tabular}{lll} 
Parameters & Method & Preparative \\
\cline { 2 - 3 } Column & Analytical & $\mathrm{C}_{18}(100 \times 19 \mathrm{~mm} \times 5 \mu \mathrm{m})$ \\
\hline Injection load & $\mathrm{C}_{18}(150 \times 4.6 \mathrm{~mm} \times 5 \mu \mathrm{m})$ & $100 \mathrm{mg}$ \\
\hline Injection volume & $1 \mathrm{mg}$ & $1 \mathrm{~mL}$ \\
\hline Flow & $20 \mu \mathrm{L}$ & $10 \mathrm{~mL}^{-\mathrm{min}^{-1}}$ \\
\hline Isocratic & $1.5 \mathrm{~mL} \cdot \mathrm{min}^{-1}$ & $(90: 20: 1)$ \\
Solvent B & $(80: 20: 1)$ & Methanol \\
\hline Solvent A & Acetonitrile & Water \\
Acid & Water & Acetic \\
\hline
\end{tabular}

equipment control and data processing were done using the software Empower Pro.

\section{4 | Anacardic acid quantification}

For AnAc quantification a previously validated HPLC method [23] was employed. The chromatographic system was composed by a binary pump (Shimadzu LC-20AB Prominence), coupled to a diode array detector (Shimadzu SPDM20A Prominence) monitored at $280 \mathrm{~nm}$ and an auto sampler (Shimadzu SIL-20AC Prominence, Kyoto, Japan). The column used was an analytical reversed phase column CLC ODS(M) $\mathrm{C}_{18}(150 \times 4.6 \mathrm{~mm}, 5 \mu \mathrm{m}$, Shimadzu Shim-pack). The AnAc triene (15:3) was used as an external standard for the analytical calibration curve which was composed by seven different concentrations (50 to $1000 \mu \mathrm{g} \cdot \mathrm{mL}^{-1}$ ).

\section{5 | Performance evaluation}

The equations employed for solvent consumption and productivity calculations $[28,29]$ were adapted to the preparative HPLC system. Solvent consumption was calculated based on volumetric flow, run time, organic solvent percentage and mass of obtained products for each injection (equation (3)).

$$
S C=\frac{t_{r u n} \cdot Q \cdot \%_{s o l}}{m_{A n A c}}
$$

Wherein, $S C$ is solvent consumption expressed in $\mathrm{mL} \cdot \mathrm{mg}^{-1}$ of anacardic acids, $t_{\text {run }}$ is time of chromatographic run, $Q$ is the flow $\left(\mathrm{mL} . \mathrm{min}^{-1}\right)$ of preparative system, $\%_{\text {sol }}$ is the percentage of organic solvent present in the mobile phase and $m_{A n A c}$ is the mass of anacardic acids present in CNSL concentration loading.

The productivity of isolation was expressed in kg.day ${ }^{-1} \cdot \mathrm{kg}^{-1}$ of adsorbent, which was calculated considering the volumetric flow, column adsorbent mass and concentration of products obtained (equation (4)).

$$
\operatorname{Pr}=\frac{Q \cdot C_{A n A c}}{m_{a d}}
$$

Wherein, $\operatorname{Pr}$ is productivity of insolation on the preparative system, $Q$ is the volumetric flow $\left(\mathrm{mL} \cdot \mathrm{min}^{-1}\right), C_{A n A c}$ is anacardic acids concentration (mg. $\mathrm{mL}^{-1}$ ) present in each CNSL concentration loading, $m_{a d}$ is the column adsorbent mass.

The recovery of three AnAc (triene, diene and monoene) isolated by preparative scale was calculated from equation 5 .

$$
m_{\text {theo }}=m_{a n .} \cdot L_{i n j}
$$

Wherein, $m_{\text {theo }}$ is theoretical mass of each AnAc in preparative scale, $m_{a n}$ is the mass of each AnAc present in $1 \mathrm{mg}$ of CNSL quantified in the analytical system (section 2.5) and $L_{i n j .}$ is the concentration loading which is amount of CNSL present in $1 \mathrm{~mL}$ (fixed volume).

The real AnAc amount recovered by preparative HPLC system was expressed in percentage (\%) according to equation 6.

$$
\text { (\%) } R_{\text {pr. }}=\frac{m_{\text {obt. }}}{m_{\text {theo. }}} \cdot 100
$$

Wherein, $(\%) R_{p r}$ is the recovery of each AnAc, $m_{o b t}$ is the real mass of AnAc; and $m_{\text {theo. }}$ is the theoretical mass of AnAc in respective load injected.

The purity of each isolated AnAc was evaluated by HPLCDAD using a validated method (item 2.4). All peaks detected were integrated and their percentage used to the purity determination. Peaks with a signal below the limit of detection (LOD $19.8 \mu \mathrm{g} \cdot \mathrm{mg}^{-1}$ ) were not considered according the values described in literature [23]. The total yield for each AnAc was expressed as the average of three chromatographic runs and expressed in $\mathrm{g} . \mathrm{kg}^{-1}$ of CNSL.

\section{3 | RESULTS AND DISCUSSION}

The chromatographic profile of different concentration loadings $(50,75,100$ and $200 \mathrm{mg})$ of CNSL is shown on Figure 1. The three main anacardic acids on CNSL AnAc triene (I), AnAc diene (II) and AnAc monoene (III) can be observed. 


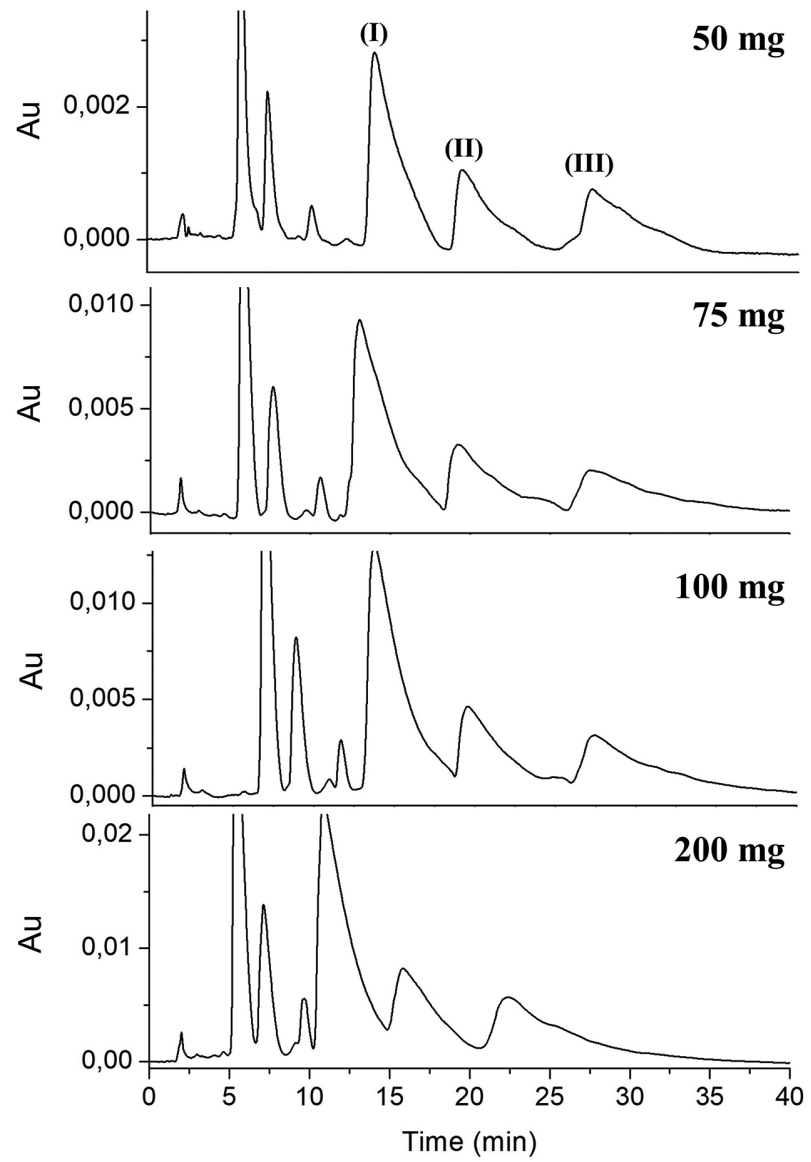

F I G U R E 1 Chromatographic profile from preparative HPLC of different concentration loads (50, 75, 100 and $200 \mathrm{mg}$ ) of CNSL, AnAc triene (I), AnAc diene (II) and AnAc monoene (III), at a wavelength of $280 \mathrm{~nm}$

The AnAc isolation was performed in three chromatographic runs for each concentration loading and the compounds were isolated at the retention times of 13.2 to $17.9 \mathrm{~min}, 18.6$ to $24.2 \mathrm{~min}$; and 26.6 to $34.5 \mathrm{~min}$, for the AnAc triene, diene and monoene, respectively.

The values of partition coefficient $(\log \mathrm{P})$ (Table 2) contributes to explain the elution behavior of organic compounds on reversed phase liquid chromatography [30,31], and consequently provide information about anacardic acids elution order. The growing values of $\log P$ of $7.69,7.99$ and 8.35 for AnAc 15:3, 15:2 and 15:1 respectively, revealed a higher hydrophobicity of AnAc monoene (15:1). Therefore the elution order of the anacardic acids on reversed phase could be justified based on these parameters. Likewise the same tendency is observed for $\log D(4.18,4.49$ and 4.85) for AnAc 15:3, 15:2 and 15:1, respectively. All AnAc showed a low solubility in water $(-8.20,-8.38$ and -8.50 for AnAc 15:3, 15:2 and $15: 1$, respectively).

The mass yield values of each isolated compound expressed in gram of AnAc per kilogram of CNSL (. $\mathrm{kg}^{-1}$ ) are shown on Table 3. The mass averages obtained for the concentration loading of $50 \mathrm{mg}$ were $311.6,146.0$ and 191.4 g. $\mathrm{kg}^{-1}$, for AnAc triene, diene and monoene, respectively. For the load of $75 \mathrm{mg}$ the yield was of 319.46, 147.06 and $111.06 \mathrm{~g} . \mathrm{kg}^{-1}$, for AnAc triene, diene and monoene, respectively. The yield for the load of $100 \mathrm{mg}$ was of $335.00,146.00$ and $129.00 \mathrm{~g} . \mathrm{kg}^{-1}$, for AnAc triene, diene and monoene, respectively. Regarding the concentration loading of $200 \mathrm{mg}$ the yield values were $255.80,140.50$ and $113.50 \mathrm{~g} . \mathrm{kg}^{-1}$, for AnAc triene, diene and monoene, respectively. The yield values should be as closer as possible independently of the concentration loading since the operational system (mobile phase, proportion of organic solvent, flow and running time) were the same. However, for the concentration loading of $200 \mathrm{mg}$ occurred a variation in the recovery (Table 3) due the column overload which caused some changes such as retention time and peak enlargement of AnAc, these changes affected directly the yield values because the time collects are set before according preset method. The values of mass obtained from 50, 75 and $100 \mathrm{mg}$ of load for triene and diene were similar with literature (358.3, 144.1 and $202.0 \mathrm{~g} . \mathrm{kg}^{-1}$, for triene, diene and monoene, respectively) [21], only monoene showed a lower amount when compared with this result. This difference can be explained by the peak tail effect caused by the less polar character of AnAc monoene ( $\log P$ 8.35), which interacts strongly with column adsorbent, thereby not leading to a complete recovery of AnAc monoene on the preset collection time range. Even so, the total amount of AnAc obtained with this isolation process is accordance to the results reported in literature $[5,32,33]$. The preparative scale isolation of ginkgolic acid (17:1), also an alkyl phenol derived from salicylic acid, resulted on a yield of $179.35 \mathrm{~g} \cdot \mathrm{kg}^{-1}$ [34] which correspond to $53 \%$ of the yield for the load of $100 \mathrm{mg}$ for AnAc (15:3) in the present work.

The recoveries of each AnAc are shown in Table 3. The percentage recovery values obtained for the concentration loadings (50 mg to $100 \mathrm{mg}$ ) varied from 82 to $97 \%$. Such values are compared to previous results for anacardic acids [21]. However, the time range for peak collection associated with the higher hydrophobicity of AnAc monoene caused a decrease in its recovery. The concentration loading of $200 \mathrm{mg}$ resulted in low percentage recovery for AcAn triene and monoene due to column saturation [35], thus showing chromatographic peaks with wider base [36] and coelution.

The chromatograms of isolated AnAc are shown in Figure 2. The purity ranged from 90.22 to $99.11 \%$ (Table 3), decreasing gradually as the concentration loading was increased, probably due to an overload causing a wider base, deformity of peaks and coelution of compounds [35,36]. Anacardic acids with side chains containing 12, 13 and 17 carbons are generally found in the CNSL [2,3] and they could be coeluted due to a similar polarity [37]. 
T A B L E 2 Physical-chemical parameters of Anacardic acids triene (15:3), diene (15:2) and monoene (15:1) with its chemical structure, values from $\log$, $\log \mathrm{D}$ and Solubility

\begin{tabular}{|c|c|c|c|c|c|}
\hline \multirow[t]{2}{*}{ AnAc } & \multirow[t]{2}{*}{ Chemical structure } & \multicolumn{2}{|c|}{$\log P$ and $\log D$} & \multicolumn{2}{|l|}{ Solubility } \\
\hline & & $\log P$ & $\log D_{(\mathrm{pH} \mathrm{7.4)}}$ & Category & Intrinsic \\
\hline$(15: 3)$ & & 7.69 & 4.18 & Low & -8.20 \\
\hline$(15: 2)$ & & 7.99 & 4.49 & Low & -8.38 \\
\hline$(15: 1)$ & & 8.35 & 4.85 & Low & -8.50 \\
\hline
\end{tabular}

T A B L E 3 Results of yield, recovery and purity from isolation process of different anacardic acids (triene, diene and monoene) from different injections load (50, 75, 100 and $200 \mathrm{mg}$ ) of CNSL

\begin{tabular}{|c|c|c|c|c|}
\hline \multirow{3}{*}{ Anacardic Acid } & \multicolumn{4}{|l|}{ Yield (g.kg $\left.{ }^{-1}\right)$} \\
\hline & \multicolumn{4}{|l|}{ Load injection } \\
\hline & $50 \mathrm{mg}$ & $75 \mathrm{mg}$ & $100 \mathrm{mg}$ & $200 \mathrm{mg}$ \\
\hline$(15: 2)$ & $146.00 \pm 17.40$ & $147.06 \pm 25.40$ & $146.00 \pm 23.40$ & $140.50 \pm 5.20$ \\
\hline$(15: 1)$ & $191.40 \pm 33.20$ & $111.06 \pm 37.60$ & $129.30 \pm 28.80$ & $113.80 \pm 16.80$ \\
\hline Anacardic Acid & $\overline{50 ~ m g}$ & $75 \mathrm{mg}$ & $100 \mathrm{mg}$ & $200 \mathrm{mg}$ \\
\hline$(15: 3)$ & $94.02 \pm 0.61$ & $93.82 \pm 6.10$ & $95.50 \pm 3.07$ & $77.18 \pm 4.59$ \\
\hline$(15: 2)$ & $87.63 \pm 3.83$ & $82.46 \pm 1.13$ & $90.68 \pm 6.79$ & $84.23 \pm 0.69$ \\
\hline$(15: 1)$ & $97.35 \pm 0.57$ & $65.57 \pm 7.04$ & $67.90 \pm 8.99$ & $57.89 \pm 5.78$ \\
\hline Anacardic Acid & \multicolumn{4}{|l|}{ Load injection } \\
\hline$(15: 3)$ & $99.11 \pm 0.49$ & $97.40 \pm 0.71$ & $96.41 \pm 0.95$ & $95.14 \pm 0.23$ \\
\hline$(15: 2)$ & $95.56 \pm 1.23$ & $95.09 \pm 1.40$ & $95.32 \pm 0.33$ & $87.73 \pm 3.17$ \\
\hline$(15: 1)$ & $92.59 \pm 0.71$ & $95.75 \pm 1.64$ & $90.77 \pm 1.85$ & $90.22 \pm 2.15$ \\
\hline
\end{tabular}

Values for solvent consumption and productivity were calculated in function of AnAc concentration obtained from different concentration loadings (Table 4). The solvent consumption for preparative scale was 11.09, 8.31, 5.89 and $3.53 \mathrm{~mL} . \mathrm{mg}^{-1}$ for $50,75,100$ and $200 \mathrm{mg}$ concentration loading, respectively. A decrease of solvent consumption is expected since a higher amount of final product is obtained as the concentration loading is increased. However, the decrease was not proportional in the concentration loading of $200 \mathrm{mg}$ since values of recovery of AnAc were affected. There was solvent volume reduction in the preparative scale to obtain AnAc when compared with other preparative isolations that consume up to $17 \mathrm{~mL} \cdot \mathrm{mg}^{-1}$ depending of characteristic of the isolated molecule [38-40]. The results of productivity were of
$0.0391,0.0482,0.0681$ and $0.1140 \mathrm{~kg} \cdot \mathrm{day}^{-1} \cdot \mathrm{kg}^{-1}$ of adsorbent for 50, 75, 100 and $200 \mathrm{mg}$ concentration loading, respectively (Table 4). The solvent consumption and productivity are deeply linked and inversely proportional [41].

\section{4 | CONCLUSION}

The preparative scale liquid chromatography was effective in the isolation process of anacardic acids achieving an efficient separation of three different AnAc triene, diene and monene. During the scale up, the yield, purity and recovery were kept viable up to the concentration loading of $100 \mathrm{mg}$. The 
mAU

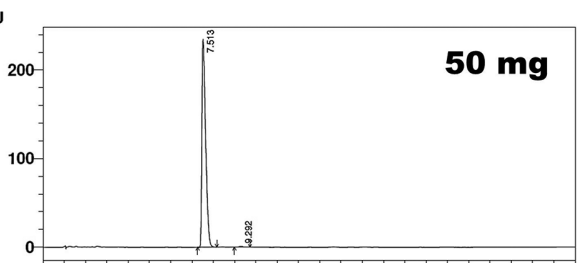

mAU

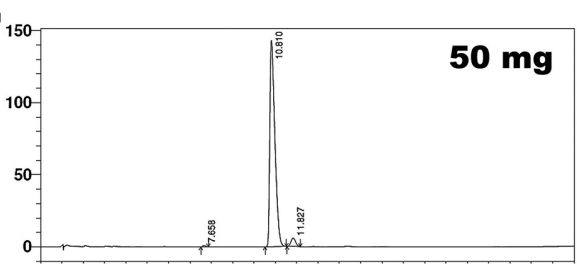

mAU
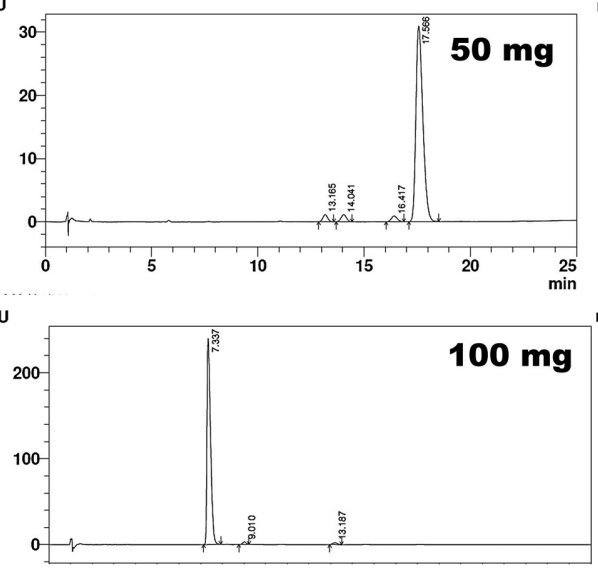

mAU

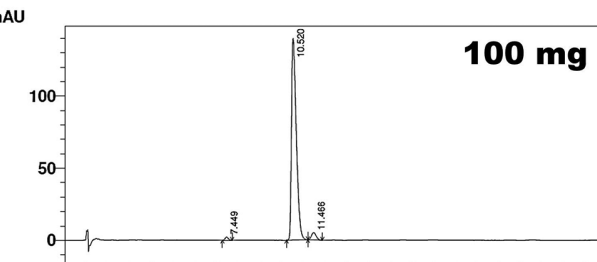

mAU

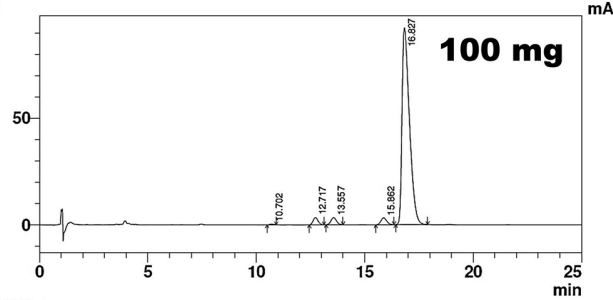

maU

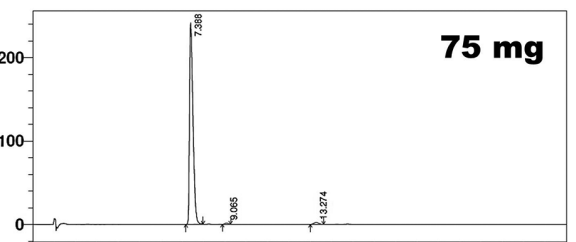

maU

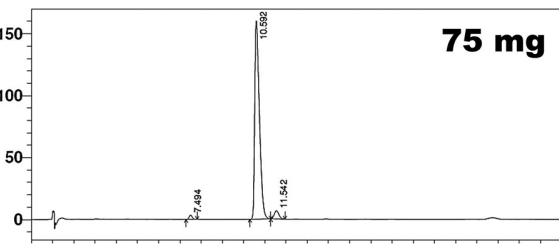

MAU

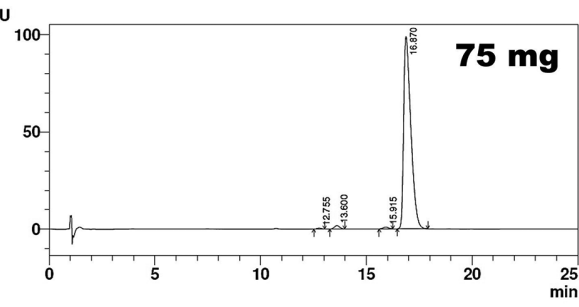

mAU

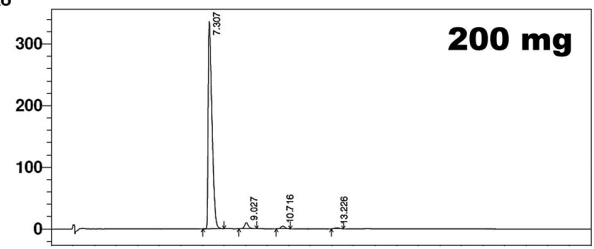

U
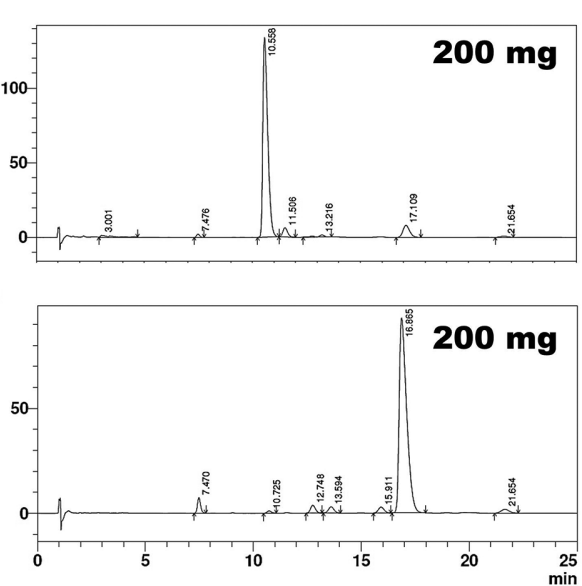

F I G U R E 2 Chromatographic profile of different anacardic acids (analytical HPLC), AnAc triene (I), AnAc diene (II) and AnAc monoene (III), isolated from different concentration loads (50, 75, 100 and $200 \mathrm{mg}$ ) of CNSL, at a wavelength of $280 \mathrm{~nm}$

T A B L E 4 Results of solvent consumption and productivity from isolation process of anacardic acids of different injections load in preparative scale $(50,75,100$ and $200 \mathrm{mg})$ and analytical scale from CNSL

\begin{tabular}{|c|c|c|c|c|c|}
\hline & \multicolumn{4}{|c|}{ Preparative load injection } & \multirow[t]{2}{*}{ Analytical scale } \\
\hline & $50 \mathrm{mg}$ & $75 \mathrm{mg}$ & $100 \mathrm{mg}$ & $200 \mathrm{mg}$ & \\
\hline Solvent Consumption (mL.mg $\left.{ }^{-1}\right)$ & 11.09 & 8.31 & 5.89 & 3.53 & 60.52 \\
\hline Productivity $\left(\mathrm{kg}\right.$. day $\left.^{-1} \cdot \mathrm{kg}^{-1}\right)$ & 0.0391 & 0.0482 & 0.0681 & 0.1140 & 0.0014 \\
\hline
\end{tabular}

*Results obtained from an analytical method [23] 
solvent consumption and productivity also show good results for the concentration loading of $100 \mathrm{mg}$ thus impacting directly and positively the feasibility of the process. Therefore, the process optimization was achieved with a concentration loading of $100 \mathrm{mg}$ as a process threshold leading to a productivity of $0.681 \mathrm{Kg}$.day ${ }^{-1} \cdot \mathrm{Kg}^{-1}$ of anacardic acids with purity of $96.41,95.32$ and $90.77 \%$ for anacardic acid triene, diene and monoene, respectively, establishing this as the optimum condition for isolation of AnAc in preparative scale. These results provide relevant data for the isolation of AnAc from CNSL, based on the best productivity $\left(0.0681 \mathrm{~kg} \cdot \mathrm{day}^{-1} \cdot \mathrm{kg}^{-1}\right)$ and low solvent consumption $\left(5.89 \mathrm{~mL} \cdot \mathrm{mg}^{-1}\right)$.

\section{ACKNOWLEDGMENTS}

This work was supported by Empresa Brasileira de Pesquisa Agropecuária, Embrapa [Grant number 03.14.03.009.00.00] and Fundação Cearense de Apoio ao Desenvolvimento Científico e Tecnológico, FUNCAP [BMD-0008-00640.01.12/15] to F.O.F.

\section{CONFLICT OF INTEREST}

The authors have declared no conflict of interest.

\section{ORCID}

Edy S. de Brito (1D) https://orcid.org/0000-0003-4084-8076

\section{REFERENCES}

1. Neto, L., Matos, N., Gonzaga, W., Romeiro, L., Santos, M., Santos, D., Motoyama, A., Characterization of cytotoxic activity of compounds derived from anacardic acid, cardanol and cardol in oral squamous cellcarcinoma. BMC Proceedings. 2014, 8(suppl), 1-2.

2. Jerz, G., Murillo-Velásquez, J. A., Skrjabin, I., Gök, R., Winterhalter, P., Recent Advances in the Analysis of Food and Flavors. ACS Publications, Washington, 2012, pp. 145-165.

3. Česla, P., Blomberg, L., Hamberg, M., Jandera, P., Characterization of anacardic acids by micellar electrokinetic chromatography and mass spectrometry. J. Chromatogr. A. 2006, 1115, 253-259.

4. Hemshekhar, M., Sebastin Santhosh, M., Kemparaju, K., Girish, K. S., Emerging roles of anacardic acid and its derivatives: a pharmacological overview. Basic Clin. Pharmacol. Toxicol. 2012, 110, 122 132.

5. Trevisan, M. T. S., Pfundstein, B., Haubner, R., Würtele, G., Spiegelhalder, B., Bartsch, H., Owen, R. W., Characterization of alkyl phenols in cashew (Anacardium occidentale) products and assay of their antioxidant capacity. Food Chem. Toxicol. 2006, 44, 188-197.

6. Kubo, I., Masuoka, N., Ha, T. J., Tsujimoto, K., Antioxidant activity of anacardic acids. Food Chem. 2005, 99, 555-562.

7. Morais, S. M., Silva, K. A., Araujo, H., Vieira, I. G. P., Alves, D. R., Fontenelle, R. O. S., Silva, A., Anacardic acid constituents from cashew nut shell liquid: NMR characterization and the effect of unsaturation on its biological activities. Pharmaceuticals. 2017, 10, 31.

8. Huang, H., Hua, X., Liu, N., Li, X., Liu, S., Chen, X., Zhao, C., Lan, X., Yang, C., Dou, Q. P., Anacardic acid induces cell apoptosis associated with induction of ATF4-dependent endoplasmic reticulum stress. Toxicol. Lett. 2014, 228, 170-178.

9. Lemes, L. F. N., Ramos, G. A., de Oliveira, A. S., da Silva, F. M. R., Couto, G. C., Boni, M. S., Guimarães, M. J. R., Souza, I. N. O., Bartolini, M., Andrisano, V., Cardanol-derived AChE inhibitors: towards the development of dual binding derivatives for Alzheimer's disease. Eur. J. Med. Chem. 2016, 108, 687-700.

10. de Oliveira, V. M., Mendes, L. M., Almeida, D. J., Hoelz, L. V. B., Torres, P. H. M., Pascutti, P. G., New treatments for Chagas disease and the relationship between chagasic patients and cancers. Cancer Res. J. 2014, 2, 11-29.

11. Hollands, A., Corriden, R., Gysler, G., Dahesh, S., Olson, J., Ali, S. R., Kunkel, M. T., Lin, A. E., Forli, S., Newton, A. C., Natural product anacardic acid from cashew nut shells stimulates neutrophil extracellular trap production and bactericidal activity. J. Biol. Chem. 2016, 291, 13964-13973.

12. Masuoka, N., Shimizu, K., Kubo, I., Natural Antioxidants and Biocides from Wild Medicinal Plants. Cabi, Nosworthy Way, Wallingford, Oxfordshire UK. 2013, pp. 137-147.

13. Jin, G., Guo, Z., Xiao, Y., Yan, J., Dong, X., Shen, A., Wang, C., Liang, X., Practical method for the definition of chromatographic peak parameters in preparative liquid chromatography. J. Sep. Sci. 2016, 39, 3917-3926.

14. Hostettmann, K., Marston, A., Hostettmann, M., Preparative chromatography techniques. Second Edition, Springer 1998.

15. Golshan-Shirazi, S., Guiochon, G., Theory of optimization of the experimental conditions of preparative elution chromatography: optimization of the column efficiency. Anal. Chem. 1989, 61, 13681382.

16. García Palacios, J., Kaspereit, M., Ziomek, G., Antos, D., SeidelMorgenstern, A., Optimization and analysis of possible column arrangements for multicomponent separations by preparative chromatography. Ind. Eng. Chem. Res. 2009, 48, 11148-11157.

17. Sousa, Â., Sousa, F., Queiroz, J. A., Advances in chromatographic supports for pharmaceutical-grade plasmid DNA purification. $J$. Sep. Sci. 2012, 35, 3046-3058.

18. Ye, X., Cao, D., Song, F., Fan, G., Wu, F., Preparative separation of nine flavonoids from Pericarpium Citri Reticulatae by preparativeHPLC and HSCCC. Sep. Sci. Technol. 2016, 51, 807-815.

19. Han, L., Boakye-Yiadom, M., Zhang, Y., Zhang, P., Liu, E., Wang, T., Gao, X., Separation and purification of two isomeric saponins from Albiziae cortex by high-speed counter-current chromatography and preparative high-performance liquid chromatography. Sep. Sci. Technol. 2014, 49, 594-600.

20. Fan, Y., Fu, Y., Fu, Q., Cai, J., Xin, H., Dai, M., Jin, Y., Purification of flavonoids from licorice using an off-line preparative twodimensional normal-phase liquid chromatography/reversed-phase liquid chromatography method. J. Sep. Sci. 2016, 39, 2710-2719.

21. Lloyd, H. A., Denny, C., Krishna, G., A simple liquid chromatographic method for analysis and isolation of the unsaturated components of anacardic acid. J. Liq. Chromatogr. 1980, 3, 14971504. 
22. Kubo, I., Komatsu, S., Ochi, M., Molluscicides from the cashew Anacardium occidentale and their large-scale isolation. J. Agric. Food Chem. 1986, 34, 970-973.

23. Oiram Filho, F., Alcântra, D. B., Rodrigues, T. H. S., Alexandre e Silva, L. M., de Oliveira Silva, E., Zocolo, G. J., Brito, E. S., Development and validation of a reversed phase HPLC method for determination of anacardic acids in cashew (Anacardium occidentale) nut shell liquid. J. Chromatogr. Sci. 2017 https://doi.org/10.1093/chromsci/bmx111.

24. Chemicalize, Calculation module developed by ChemAxon https://chemaxon.com/products/chemicalize (last time accessed: 25/10/2018), 2018.

25. Guillarme, D., Nguyen, D. T., Rudaz, S., Veuthey, J., Method transfer for fast liquid chromatography in pharmaceutical analysis: application to short columns packed with small particle. Part I: isocratic separation. Eur. J. Pharm. Biopharm. 2007, 66, 475-482.

26. Aubin, A., Cleary, R., Analytical HPLC to preparative HPLC: scaleup techniques using a natural product extract. Waters Application Note 720003120 EN 2009.

27. Snyder, L. R., Kirkland, J. J., Glajch, J. L., Preparative HPLC Separation. Practical HPLC Method Development, Second Edition 2012, 616-642.

28. Arcanjo, M. R. A., Fernandes, F. A. N., Silva Jr, I. J., Separation of lactic acid produced by hydrothermal conversion of glycerol using ion-exchange chromatography. Adsorpt. Sci. Technol. 2015, $33,139-151$

29. Silva Jr, I. J., Veredas, V., Santos, M. A. G., Santana, C. C., Carpes, M. J. S., Correia, C. R. D., Cromatografia em leito móvel simulado na produção de substâncias enantiomericamente puras ou enriquecidas em larga escala. Quím. Nova. 2006, 29, 1027-1037.

30. Liang, C., Qiao, J., Lian, H., Determination of reversed-phase high performance liquid chromatography based octanol-water partition coefficients for neutral and ionizable compounds: Methodology evaluation. J.Chromatogr. A. 2017, 1528, 25-34.

31. Liang, C., Lian, H., Recent advances in lipophilicity measurement by reversed-phase high-performance liquid chromatography. Trends Anal. Chem. 2015, 68, 28-36.

32. Gandhi, T. S., Dholakiya, B.Z., Patel, M. R., Extraction protocol for isolation of CNSL by using protic and aprotic solvents from cashew nut and study of their physico-chemical parameter. Pol. J. Chem. Technol. 2013, 15, 24-27.

33. Paramashivappa, R., Kumar, P. P., Vithayathil, P. J., Rao, A. S., Novel method for isolation of major phenolic constituents from cashew (Anacardium occidentale L.) nut shell liquid. J. Agric. Food Chem. 2001, 49, 2548-2551.

34. van Beek, T. A., Wintermans, M. S., Preparative isolation and dual column high-performance liquid chromatography of ginkgolic acids from Ginkgo biloba. J. Chromatogr. A 2001, 930, 109-117.

35. McChesney, J. D., Rodenburg, D. L., Preparative chromatography and natural products discovery. Curr. Opin. Biotechnol. 2014, 25, $111-113$

36. Sardella, R., Ianni, F., Marinozzi, M., Macchiarulo, A., Natalini, B., Laboratory-scale preparative enantioseparations of pharmaceutically relevant compounds on commercially available chiral stationary phases for HPLC. Curr. Med. Chem. 2017, 24, 796817.

37. Yuliana, M., Nguyen-Thi, B. T., Faika, S., Huynh, L. H., Soetaredjo, F. E., Ju, Y., Separation and purification of cardol, cardanol and anacardic acid from cashew (Anacardium occidentale L.) nut-shell liquid using a simple two-step column chromatography. J. Taiwan Inst. Chem. Eng. 2014, 45, 2187-2193.

38. Bae, Y., Moon, J., Lee, C., Effects of feed concentration on the startup and performance behaviors of simulated moving bed chromatography. Ind. Eng. Chem. Res. 2006, 45, 777-790.

39. Grill, C. M., Miller, L., Yan, T. Q., Resolution of a racemic pharmaceutical intermediate: A comparison of preparative HPLC, steady state recycling, and simulated moving bed. J. Chromatogr. A 2004, 1026, 101-108.

40. Miller, L., Grill, C. M., Yan, T., Dapremont, O., Huthmann, E., Juza, M., Batch and simulated moving bed chromatographic resolution of a pharmaceutical racemate. J. Chromatogr. A 2003, 1006, 267280 .

41. Yoshimoto, N., Sugiyama, Y., Yamamoto, S., A simple method for calculating the productivity of polyphenol separations by polymerbased chromatography. Biosci. Biotechnol. Biochem. 2017, 81, 812816.

How to cite this article: Filho FO, Zocolo GJ, Canuto KM, Junior IJdS, de Brito ES. Productivity of a preparative high performance liquid chromatography isolation of anacardic acids from cashew nut shell liquid. Sep Sci plus 2019;2:192-199. https://doi.org/10.1002/sscp.201900014 